\title{
Cortical unlike trabecular bone loss is not associated with vascular calcification progression in CKD patients
}

\author{
Larissa R. Costa ${ }^{1 *}$, Aluizio B. Carvalho ${ }^{1}$, Amandha L. Bittencourt ${ }^{1}$, Carlos E. Rochitte ${ }^{2}$ and Maria Eugênia F. Canziani ${ }^{1}$
}

\begin{abstract}
Background: Vascular calcification progression has been associated with the loss of trabecular bone in chronic kidney disease (CKD) patients. There are few data evaluating the relationship between cortical bone loss and vascular calcification in this population. The aim of this study was to prospectively evaluate the association between changes in cortical bone density and coronary artery calcification (CAC) progression in non-dialyzed CKD patients.

Methods: Changes of cortical and trabecular bone, and changes of calcium score, were analyzed using vertebral tomographic images from a prospective study. Automatic delineation of the cortical bone layer was performed by Image J software, and trabecular bone was determined by selecting a region of interest using Vitrea $2^{\circledR}$ software. Cortical and trabecular bone density (BD) were expressed in Hounsfield Units (HU), and coronary artery calcium score in Agatston Units (AU).
\end{abstract}

Results: Seventy asymptomatic patients $[57.8 \pm 10.2$ years, $63 \%$ males, 20\% diabetic, estimated glomerular filtration rate $(e G F R)=37.3(24.8-51.3) \mathrm{mL} / \mathrm{min} / 1.73 \mathrm{~m}^{2}$ ] were followed for 24 months. The mean cortical and trabecular BD did not change over time. While 49 patients lost either bone, 29 (41\%) patients lost cortical [-4.4\%/year (ranging from -7.15 to -0.5$)$ ] and $39(56 \%)$ lost trabecular bone [-3.15\%/year $(-13.7$ to -0.25$)]$. There was no association between cortical and trabecular BD changes $(p=0.12$ ). CAC was observed in $33(46 \%)$ patients at baseline, and 30 $(91 \%)$ of them showed CAC progression. While an inverse correlation between trabecular bone and calcium score changes was observed $(p=0.001)$, there was no correlation between cortical bone and calcium score changes $(p=0.34)$.

Conclusion: CKD patients experience either cortical or trabecular bone loss over time, but these changes do not take place simultaneously in all patients. Cortical, unlike trabecular bone loss, is not associated with vascular calcification progression in these patients.

Keywords: Cortical bone, Trabecular bone, Vascular calcification, Chronic kidney disease

\footnotetext{
* Correspondence: larissadbr@hotmail.com

${ }^{1}$ Nephrology Division of Federal University of São Paulo, Rua Pedro de

Toledo, 282 - Vila Clementino, São Paulo, SP 04039-000, Brazil

Full list of author information is available at the end of the article
}

(c) The Author(s). 2020 Open Access This article is licensed under a Creative Commons Attribution 4.0 International License, which permits use, sharing, adaptation, distribution and reproduction in any medium or format, as long as you give appropriate credit to the original author(s) and the source, provide a link to the Creative Commons licence, and indicate if changes were made. The images or other third party material in this article are included in the article's Creative Commons. licence, unless indicated otherwise in a credit line to the material. If material is not included in the article's Creative Commons licence and your intended use is not permitted by statutory regulation or exceeds the permitted use, you will need to obtain permission directly from the copyright holder. To view a copy of this licence, visit http://creativecommons.org/licenses/by/4.0/. The Creative Commons Public Domain Dedication waiver (http://creativecommons.org/publicdomain/zero/1.0/) applies to the data made available in this article, unless otherwise stated in a credit line to the data. 


\section{Background}

Structural and metabolic differences between trabecular and cortical bone have already been described. While cortical bone is a dense, low-porosity and less metabolically active tissue, trabecular bone is a honeycomb-like trabecular network with a larger remodeling area and higher turnover rate [1]. These intrinsic features go along with different key roles of each type of bone tissue, e.g., mechanical strength for cortical and mineral homeostasis for trabecular bone [2].

The disturbed bone remodeling cycle present on chronic kidney disease-mineral bone disorders (CKD-MBD) impairs bone turnover and mineralization, leading to reduced bone mass and quality [3]. Most of the knowledge on bone metabolism in chronic kidney disease (CKD) patients comes from studies performed on trabecular bone. However, recently, a prospective study showed an increase of cortical porosity in hemodialysis patients, suggesting that cortical bone may contribute to the bone loss observed in this population [4].

Bone loss has been associated with vascular calcification and both contribute to high morbidity and mortality rates in CKD patients [5]. Data regarding this association, using Dual-energy X-ray absorptiometry (DXA), have controversial results [6], as spine bone mineral density (BMD) may be overestimated by the presence of aorta calcification and osteoarthritis. Cross-sectional [7] and prospective [8] studies using quantitative computerized tomography (QCT) have shown that trabecular bone loss has been associated with vascular calcification in CKD patients. This method has shown to be a better alternative to DXA, as besides reducing BMD measurement errors, it allows trabecular and cortical bone differentiation [3, 9]. Moreover, Carvalho et al. [10] have shown that trabecular bone density, measured at the thoracic vertebra through QCT imaging, correlated to bone histomorphometric parameters in hemodialysis patients.

There is no study evaluating cortical bone and vascular calcification in the CKD scenario. It is important to mention that cortical bone comprises $80 \%$ of the human skeleton and one could hypothesize that any loss of bone from this compartment could represent a huge load of calcium driven to vessels. Therefore, the aim of this study was to evaluate, through QCT images, the relationship between changes of cortical bone density and coronary artery calcification (CAC) progression in non-dialyzed CKD patients.

\section{Methods}

\section{Patients and study protocol}

This study is a post hoc analysis of a prospective study that aimed to investigate the association of trabecular bone changes and vascular calcification progression during a 24-month follow-up [8]. In that study, 72 CKDstage 2 to 4 asymptomatic patients, from 18 to 70 years- old, were evaluated. Exclusion criteria were clinical evidence of chronic inflammatory disease, active malignancy, human immunodeficiency virus infection, viral hepatitis or chronic use of steroids and patients referred to nephrologists less than 3 months.

The patients underwent an assessment of their clinical history, physical examination and laboratory tests. CKD duration was considered as the length between the diagnosis and the enrollment into the study. Thoracic images from a multi-slice computerized tomography scanner (Somatron Volume Zoom Siemens AG, Erlangen, Germany) were evaluated to measure cortical and trabecular vertebral bone density and coronary calcium score. Cortical images were scored by 2 observers and interobserver variability was $<1 \%$. The data from only one observer were used for the analyses. Cortical bone images of 2 patients were not available. Therefore 70 out of 72 patients were evaluated in the present study.

The patients were on regular use of angiotensinconverting enzyme inhibitors (83\%), diuretics $(71 \%)$, $\beta$ blockers (43\%), calcium channel blockers (37\%), sevelamer (33\%), statins (29\%), angiotensin receptor blockers (19\%), bicarbonate (17\%), calcium-based phosphate binders $(6 \%)$, calcitriol (6\%) and erythropoietin-alpha (3\%).

This study was reviewed and approved by the Ethics Advisory Committee of the Federal University of São Paulo (no. 1113186).

\section{Vertebral bone density \\ Cortical bone}

Cortical bone density was evaluated at baseline and 24month, by Image J software (Image J 1.49v, National Institutes of Health, Bethesda, Maryland, USA, 1997-2016) $[11,12]$. A DICOM image (16 bits) was selected from the vertebral body in the axial section at the level of the aortic root (Fig. 1a). This image was converted into an 8-bit image which allowed the transformation into a binary image and generation of a cortical mask through the automatic delineation of the cortical bone layer (Fig. 1b), using the threshold function with Niblack algorithm and radius 4. This generated cortical mask was overlapped on the original image (DICOM 16 bits) and cortical bone density was automatically measured (Fig. 1c). Cortical bone densities were expressed in Hounsfield Units (HU). Bone density changes were calculated as the difference between 24month and baseline densities/baseline density"100, expressed by \%/year. Bone loss was defined as any bone density change below zero.

\section{Trabecular bone}

Trabecular bone density was evaluated at baseline and 24-month by selecting a region of interest placed at mid-vertebral body (Fig. 2) using Vitrea $2^{\circ}$ workstation software (Vital Images Inc., Plymouth, MN) [7, 10]. 


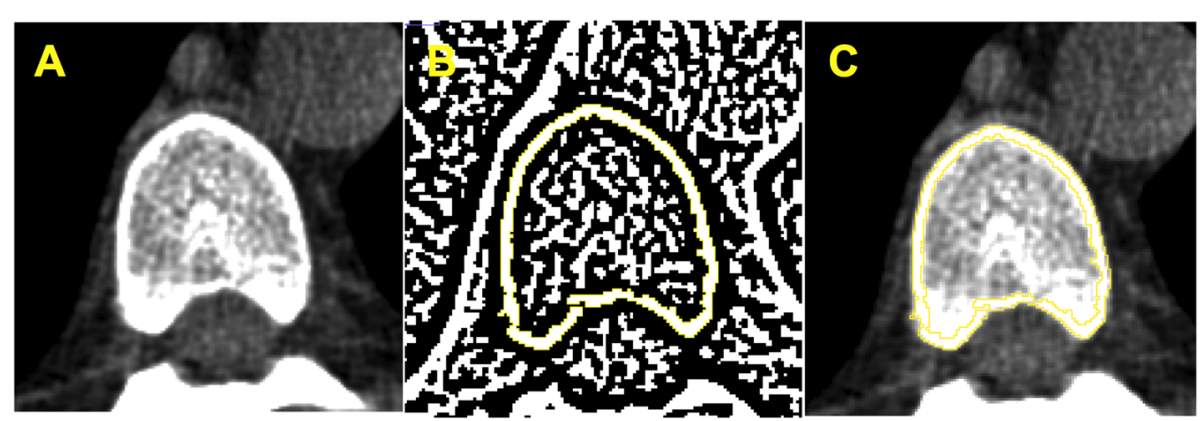

Fig. 1 Cortical vertebral tomography. a Axial vertebral image selection. b Transformation into binary image and generation of a cortical mask through the automatic delineation of cortical bone layer performed by Image J software ${ }^{\oplus}$. C - Overlapped cortical mask on the original image followed by automatic cortical density measurement

Trabecular bone densities were expressed in HU. Bone density changes were calculated as the difference between 24-month and baseline densities/baseline density*100, expressed by \%/year. Bone loss was defined as any bone density change below zero.

\section{Coronary artery calcification (CAC)}

The calcium score was obtained by multi-slice computerized tomography as described elsewhere [13]. Calcium score was expressed in Agatston Units (AU) and the presence of CAC was defined as calcium score $\geq 10 \mathrm{AU}$. CAC progression was calculated as the difference between 24-month and baseline scores/baseline score ${ }^{*} 100$.

\section{Laboratory tests}

Laboratory analyses at baseline and 24-month included: serum creatinine, hemoglobin, lipid profile, bicarbonate, ionized calcium, phosphate, alkaline phosphatase, $24 \mathrm{~h}$

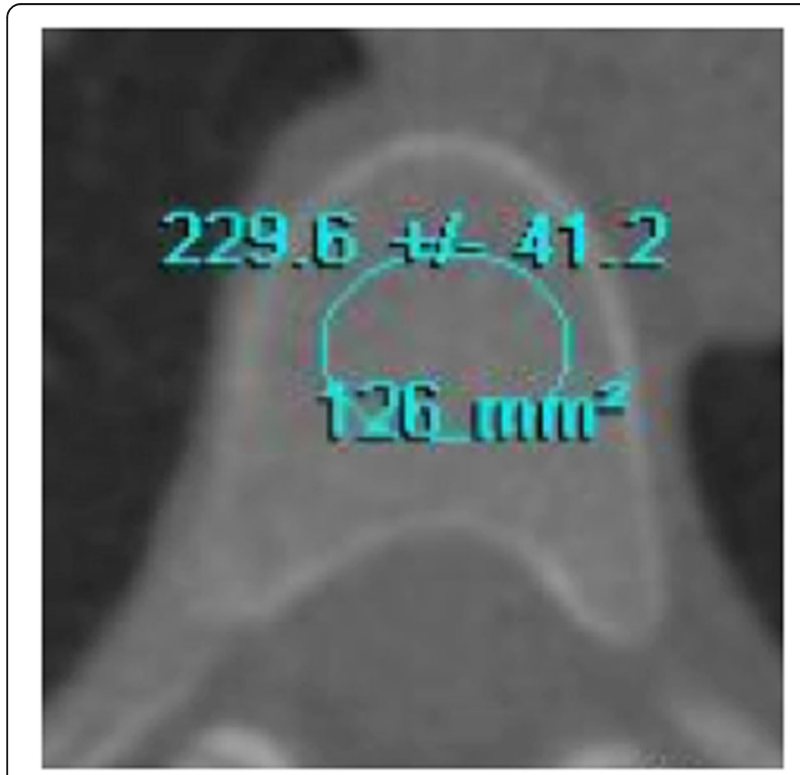

Fig. 2 Trabecular vertebral tomography proteinuria measured by standard methods, and intact parathyroid hormone (iPTH) by chemiluminescence immunoassay (Immulite; DPC-Biermann, Bad Nauheim, Germany). The glomerular filtration rate was calculated by CKD-EPI equation [14].

\section{Statistical analysis}

All variables were presented as mean and standard deviation, median and interquartile range or frequencies. The distribution of data was evaluated by KolmogorovSmirnov statistical test. The continuous variables were compared using Student's t-test or Wilcoxon, as appropriate, and proportions by McNemer tests. Univariate associations were analyzed by Pearson's or Spearman's tests according to the distribution of the variables.

Variables selected in univariate analyses were fed into multivariate linear regression models to verify their independent association with the change of cortical and trabecular bone.

$P$-values $<0.05$ were considered statistically significant. All statistical analysis was performed using SPSS for Windows (SPSS 18.0, Chicago, IL, USA).

\section{Results}

The baseline and 24-month demographic, laboratory and tomographic data are presented in Table 1. Patients were predominantly middle-aged males. Obesity [body mass index $\left.(\mathrm{BMI}) \geq 30 \mathrm{~kg} / \mathrm{m}^{2}\right]$ was found in $31 \%$ of the patients, overweight $\left(\mathrm{BMI} \geq 25 \mathrm{~kg} / \mathrm{m}^{2}\right)$ in $29 \%$, and $\mathrm{BMI}<18.5 \mathrm{~kg} / \mathrm{m}^{2}$ in only 1 patient. Diabetes and smoking were observed in 20 and $51 \%$ of the patients, respectively. According to the CKD classification [15], 8 (11\%) patients were in stage 2, 14 (20\%) in stage 3a, 24 (34\%) in stage $3 \mathrm{~b}$ and 24 (34\%) in stage 4.

During the follow-up, there was a decline in renal function and an increase in proteinuria. Total, LDL and HDLcholesterol decreased, while triglycerides levels remained unchanged. Alkaline phosphatase and iPTH did not change over time, while ionized calcium increased and phosphate levels decreased. 
Table 1 Patients characteristics at baseline and 24 months $(n=70)$

\begin{tabular}{|c|c|c|c|}
\hline & Baseline & 24 months & $p$ \\
\hline \multicolumn{4}{|l|}{ Demography } \\
\hline Age (years) & $57.8 \pm 10.2$ & & \\
\hline Males (\%) & $44(63)$ & & \\
\hline Body mass index $\left(\mathrm{kg} / \mathrm{m}^{2}\right)$ & $26.4(22.8-31.3)$ & & \\
\hline Diabetes (\%) & $14(20)$ & & \\
\hline Smoking (\%) & $36(51.4)$ & & \\
\hline CKD duration (months) & $25.4 \pm 1.3$ & & \\
\hline \multicolumn{4}{|l|}{ Laboratory } \\
\hline eGFR (mL/min/1.73m²) & $37.3(24.8-51.3)$ & $31.2(20.3-51)$ & $<0.001$ \\
\hline Proteinuria (g/24 h) & $0.19(0-0.49)$ & $0.43(0-1)$ & $<0.001$ \\
\hline Hemoglobin (g/dL) & $13.3 \pm 1.6$ & $12.9 \pm 4.4$ & $<0.001$ \\
\hline Total cholesterol (mg/dL) & $183(161-205)$ & $158(131-188)$ & $<0.001$ \\
\hline HDL-cholesterol (mg/dL) & $49(41-57)$ & $41(35-48)$ & $<0.001$ \\
\hline LDL-cholesterol (mg/dL) & $104(85-119)$ & $87(68-106)$ & 0.001 \\
\hline Triglycerides (mg/dL) & $129(99-211)$ & $127(89-177)$ & 0.20 \\
\hline Bicarbonate (mmol/L) & $21.9 \pm 3.0$ & $25.5 \pm 3.8$ & $<0.001$ \\
\hline Phosphate (mg/dL) & $3.7(3.1-4.0)$ & $3.4(3.1-3.8)$ & 0.04 \\
\hline lonized calcium (mmol/L) & $1.29 \pm 0.06$ & $1.32 \pm 0.07$ & 0.003 \\
\hline Alkaline Phosphatase (U/L) & 79 (63-93) & 70.5 (60.8-94) & 0.17 \\
\hline Intact PTH (pg/mL) & $88(61-153)$ & $98(56.5-171)$ & 0.63 \\
\hline \multicolumn{4}{|l|}{ Tomography } \\
\hline Trabecular Bone Density (HU) & $202.9 \pm 50.5$ & $202.5 \pm 51$ & 0.91 \\
\hline Cortical Bone Density (HU) & $400 \pm 89.9$ & $404 \pm 94.8$ & 0.40 \\
\hline Coronary calcium score (AU) & $5.5(0-283.8)$ & $7.5(0-385.3)$ & $<0.001$ \\
\hline
\end{tabular}

The mean cortical and trabecular bone density did not change. However, 49 out of 70 patients (70\%) lost either cortical or trabecular bone. Regarding that, 29 (41\%) patients lost cortical $[-4.4 \% /$ year (ranging from -7.15 to - 0.5); (Fig. 3a)], while 39 (56\%) lost trabecular bone [$3.15 \% /$ year $(-13.7$ to -0.25$)$; (Fig. 3b)], over time. Figure $3 \mathrm{c}$ shows the changes in the cortical and trabecular bone of each patient. Nineteen (27\%) patients lost cortical and trabecular bone simultaneously.

Coronary calcium scores significantly increased during the study (Table 1). CAC was observed in 33 (46\%) patients at baseline and CAC progression in $30(91 \%)$ out of them.

Table 2 depicts the correlations between cortical and trabecular bone density changes with the other variables. Cortical bone change correlated to HDL-cholesterol ( $\mathrm{r}=$ $0.26 ; p=0.03$ ), while trabecular bone change inversely correlated to the duration of CKD $(\mathrm{r}=-0.25 ; p=0.04)$. The cortical bone change was associated with smoking $(-1.07 \pm 8.2$ vs. $3.73 \pm 10.5 \mathrm{HU}$, smoker and nonsmoker, respectively; $\mathrm{p}=0.04$ ). No difference in cortical and trabecular bone changes regarding gender, presence of diabetes, obesity, use of medicines or other laboratory parameters was observed. Noticeable, no correlation between cortical and trabecular bone density changes $(\mathrm{r}=$ $0.19 ; p=0.12$ ) was observed.

Figure 4 shows the relationship between cortical (Fig. 4a) and trabecular (Fig. 4b) bone densities with vascular calcification progression. There was no correlation between cortical bone and calcium score changes, while an inverse correlation between changes of trabecular bone and calcium score was observed.

Multivariate models analysis showed no correlations between cortical changes and calcium score changes, even after adjusted to HDL changes and smoking ( $p=$ 0.11; IC 95\% -0.6 / 5.5). Trabecular changes correlated to calcium score changes, adjusted to duration of CKD $(p=0.03$; IC 95\% $3.3 /$-0.2).

There was no difference in calcium score change between patients who have lost or gained cortical bone (92.1 \pm 87 vs. $68.7 \pm 60.6 \mathrm{AU}$, respectively; $p=0.32$ ). On the other hand, patients who have lost trabecular bone had a higher calcium score change compared to those who gained $(134 \pm 94$ vs. $45 \pm 28 \mathrm{AU}$, respectively; $p=0.005)$. 


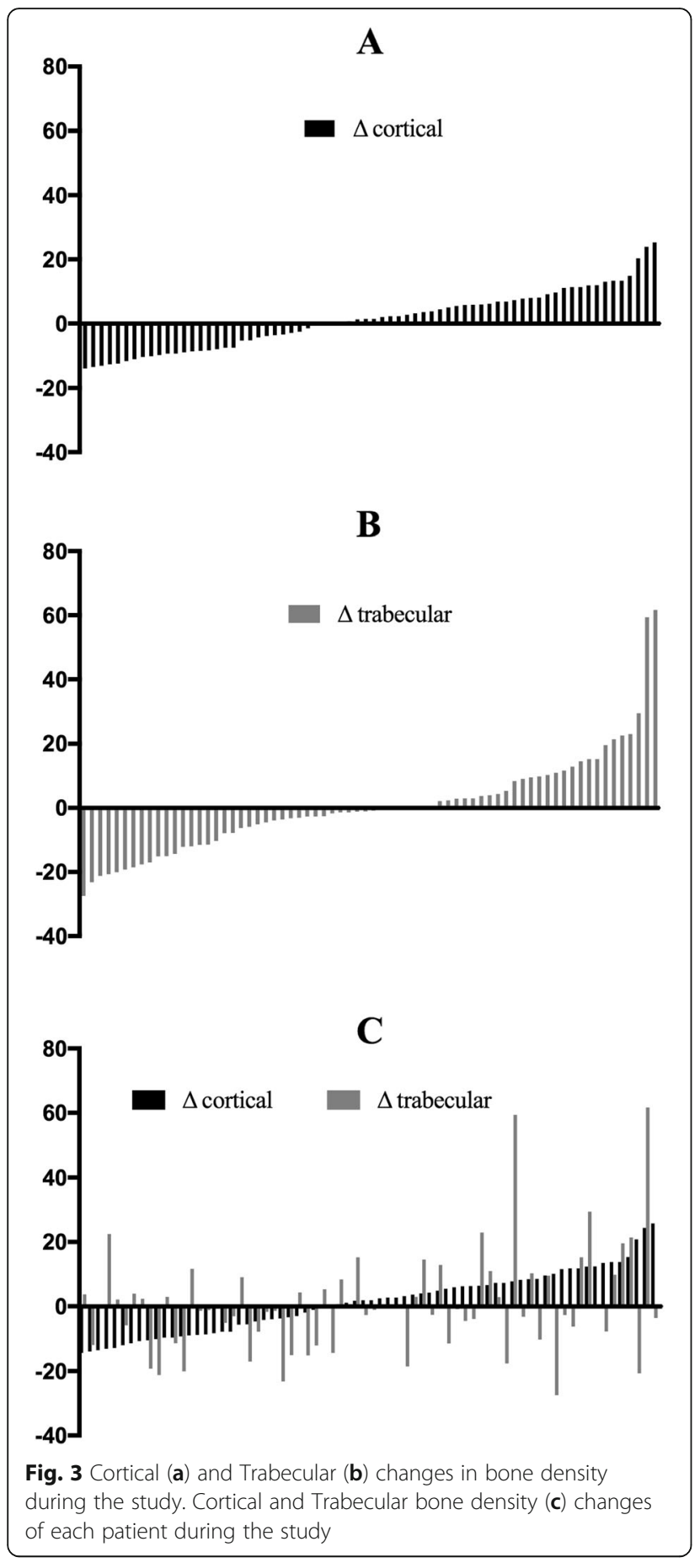

\section{Discussion}

This is a prospective study that assessed cortical and trabecular bone density changes and their relationship with vascular calcification progression in CKD patients. During the study, about half of the patients lost either cortical or trabecular bone. It is worth mentioning that both losses did not take place simultaneously in all patients. In addition, vascular calcification progression occurred in almost all calcified patients and was not associated, in the same manner, to cortical or trabecular bone loss.

The link between bone loss and cardiovascular disease either in CKD [16-19] or non-CKD population [20] has been extensively discussed in the literature. In the present study, using vertebral QCT images, we could show a distinct potential role of each type of bone tissue on vascular calcification progression. Confirming previous data, there was an association between CAC progression and trabecular bone loss $[8,21]$. To the best of our knowledge there was no study evaluating cortical bone and vascular calcification in CKD scenario. In the present study, no relation between cortical bone loss and vascular calcification was observed. This opposite behavior, between cortical and trabecular bone, could be explained by different structural and metabolic characteristics of either bone tissues.

Compared to trabecular bone, cortical bone is denser, has lower porosity and turnover rate. These characteristics grant to cortical bone a relevant biomechanical strength function. On the other hand, the trabecular bone has a larger remodeling area and a higher turnover rate indicating an active and relevant metabolic function [1,2]. Thus, the lower metabolic cortical activity, may explain the lack of association between cortical bone loss and vascular calcification progression observed in this study.

It is well known that bone loss, disregarding the method of measurement, is a frequent finding in CKD, with a prevalence varying up to $100 \%$ of the patients [22, 23]. Similarly, in the present study, $70 \%$ of the patients experienced cortical and/or trabecular bone loss after 2 years of follow-up. On the other hand, data concerning the magnitude of bone

Table 2 Univariate analysis of cortical and trabecular vertebral bone density changes

\begin{tabular}{|c|c|c|c|c|}
\hline & \multicolumn{2}{|c|}{ Cortical Change } & \multicolumn{2}{|c|}{ Trabecular Change } \\
\hline & $r$ & $p$ & $r$ & $p$ \\
\hline Age & 0.01 & 0.96 & 0.12 & 0.31 \\
\hline CKD duration & -0.04 & 0.74 & -0.25 & 0.04 \\
\hline Body mass index & 0.11 & 0.35 & 0.12 & 0.33 \\
\hline$\Delta \mathrm{eGFR}$ & 0.02 & 0.90 & 0.22 & 0.07 \\
\hline$\Delta \mathrm{LDL}$-cholesterol & 0.09 & 0.46 & -0.15 & 0.24 \\
\hline$\Delta \mathrm{HDL}$-cholesterol & 0.26 & 0.03 & 0.05 & 0.69 \\
\hline$\Delta$ triglycerides & -0.02 & 0.86 & -0.02 & 0.85 \\
\hline$\Delta$ bicarbonate & 0.11 & 0.37 & 0.25 & 0.05 \\
\hline$\Delta$ phosphorus & -0.02 & 0.90 & 0.02 & 0.91 \\
\hline$\Delta$ ionized calcium & -0.05 & 0.68 & 0.55 & 0.66 \\
\hline$\Delta$ alkaline phosphatase & -0.29 & 0.82 & 0.83 & 0.50 \\
\hline$\Delta$ intact PTH & -0.04 & 0.75 & -0.08 & 0.51 \\
\hline$\Delta$ trabecular bone density & 0.19 & 0.12 & - & - \\
\hline$\Delta$ cortical bone density & - & - & 0.19 & 0.12 \\
\hline
\end{tabular}

$\Delta=$ change, $C K D$ Chronic kidney disease, eGFR Estimated glomerular filtration rate 

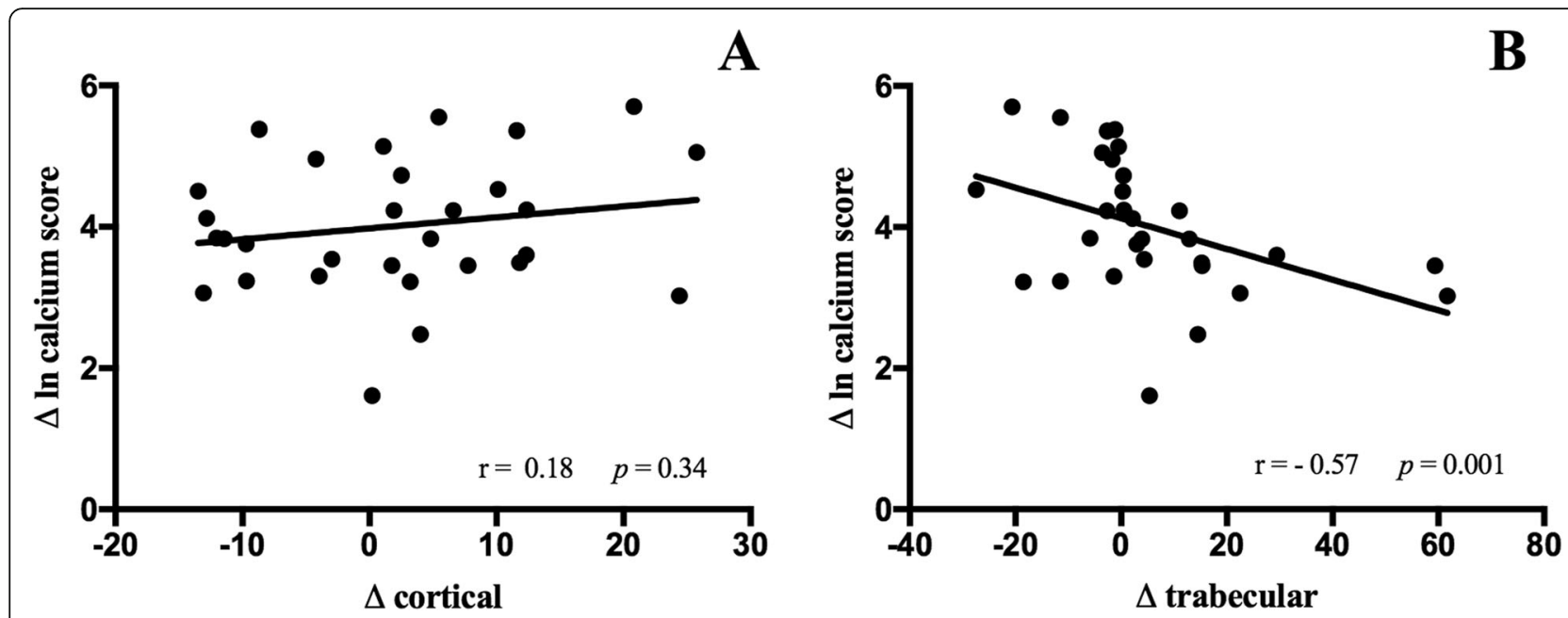

Fig. 4 Correlation between calcium score change and cortical (a) and trabecular (b) bone density changes

loss varies widely. In the present study a high rate of bone loss was observed $(-4.4 \%$ year for cortical and $-3.1 \%$ year for trabecular bone). Previous prospective studies in CKD patients, found a rate of bone loss, ranging from -4.1 to $0.7 \% /$ year, depending on the analyzing method (DXA or QCT), the skeletal site (hip or radius), the population characteristics (predialysis or dialysis) and the presence of fracture $[23,24]$.

Among those factors, the image method employed seems to be one of the utmost importance. In fact, DXA, the most common and available method used, is an imaging test that measures bone mass at specific sites. This method cannot discriminate trabecular and cortical bone, and may overestimate bone density measurements due to the presence of some conditions, such as arthritis and vascular calcification [25-27]. On the other hand, high-resolution imaging tools, as high-resolution peripheral QCT (HD-pQCT), are able to evaluate bone density and microarchitecture, as well. However, this is a highcost and routinely worldwide unavailable method [2831]. Finally, thoracic vertebral QCT showed to be a feasible tool. This new method, employed in the present study, allows simultaneous and prospective assessment of vascular calcification and bone mass changes over time. Moreover, it offers the possibility of a non-invasive and more cost-effective method that evaluates separately cortical and trabecular bone density without contamination of osteophytes and aortic calcification [32, 33].

Limitations of this study should be addressed. It is a post hoc study, with a relative small sample size that did not permit to calculate the power of such study. Moreover, the method of cortical bone measurement has not been validated yet, and its least significant change was not established. However, the scientific image-analysis program, Image J, has been widely used in the health field $[11,12]$ and recently, the evaluation of the cortical bone by image methods has been considered more accurate than the goldstandard method, e.g., bone biopsy [34, 35]. Noteworthy, we have previously validated the use of QCT for trabecular bone in predialysis CKD patients [10]. Moreover, other authors using HR-pQCT could demonstrate an inverse correlation between cortical density and cortical bone porosity, in hemodialysis patients [36].

\section{Conclusion}

CKD patients experience either cortical or trabecular bone loss over time, but these changes do not take place simultaneously in all patients. Cortical, unlike trabecular bone loss, is not associated with vascular calcification progression in these patients.

\section{Abbreviations \\ CKD-MBD: Chronic kidney disease-mineral bone disorders; CKD: Chronic kidney disease; DXA: Dual-energy X-ray absorptiometry; BMD: Bone mineral densitometry; QCT: Quantitative computed tomography; CAC: Coronary artery calcification; HU: Hounsfield Unit; AU: Agatston Unit; iPTH: Intact parathyroid hormone; CKD-EPI: Chronic kidney disease epidemiology collaboration; BMl: Body mass index; LDL: Low-density lipoprotein; HDL: High-density lipoprotein; HR-pQCT: High resolution peripheral quantitative computerized tomography}

\section{Acknowledgements}

Not applicable.

\section{Authors' contributions}

Study design: LRC, ABC, CER and MEFC. Study conduct: LRC, ABC and MEFC. Data collection: LRC and ALB. Data analysis: LRC, ABC and MEFC. Data interpretation: $L R C, A B C, C E R$ and MEFC. Drafting manuscript: $L R C, A B C$ and MEFC. Revising manuscript content: $L R C, A B C$ and MEFC. Approving final version of manuscript: $L R C, A B C, A L B, C E R$ and MEFC. LRC and MEFC takes responsibility for the integrity of the data analysis. The authors read and approved the final manuscript.

\section{Funding}

Organizations that funded this research: LRC and MEFC are supported by CNPq, Conselho Nacional de Desenvolvimento Científico e Tecnologico. This financial support had no role in the study design, collection, alalysis and interpretation of the data, the writing of the report, and the decision to submit report for publication. 


\section{Availability of data and materials}

The datasets used and/or analyzed during the current study are available from the corresponding author on reasonable request.

\section{Ethics approval and consent to participate}

This study was reviewed and approved by the Ethics Advisory Committee of the Federal University of São Paulo (no. 1113186) and this committee waived the need for an informed consent formulary since the main objective of our study was to reassess the images already obtained in a previous study [8]. And, on the occasion of that previous study, a written informed consent was obtained from all patients.

\section{Consent for publication}

Not applicable.

\section{Competing interests}

The authors declare that they have no competing interests.

\section{Author details}

${ }^{1}$ Nephrology Division of Federal University of São Paulo, Rua Pedro de Toledo, 282 - Vila Clementino, São Paulo, SP 04039-000, Brazil. ${ }^{2}$ Heart Institute of the University of São Paulo, Av. Dr. Enéas Carvalho de Aguiar, 44 Pacaembu, São Paulo, SP 05403-900, Brazil.

\section{Received: 18 June 2019 Accepted: 5 March 2020}

Published online: 06 April 2020

\section{References}

1. Clark B. Normal Bone Anatomy and Physiology. Clin J Am Soc Nephrol. 2008;3(Supl 3):S131-9.

2. Leonard MB. A structural approach to skeletal fragility in chronic kidney disease. Semin Nephrol. 2009;29(2):133-43.

3. McNerny EMB, Nickolas TL. Bone quality in chronic kidney disease: definitions and diagnostics. Curr Osteoporos Rep. 2017;15:207-13.

4. Araújo MJ, Karohl C, Elias RM, Barreto FC, Barreto DV, Canziani ME, Carvalho $A B$, Jorgetti $V$, Moyses RM, et al. The pitfall of treating low bone turnover: effects on cortical porosity. Bone. 2016:91:75-80.

5. Moe SM. Vascular calcification and renal osteodystrophy relationship in chronic kidney disease. Eur J Clin Investig. 2006;36(Suppl. 2):51-62.

6. Toussaint ND, Lau KK, Strauss BJ, Polkinghorne KR, Kerr PG. Associations between vascular calcification, arterial stiffness and bone mineral density in chronic kidney disease. Nephrol Dial Transplant. 2008;23(2):586-93.

7. Filgueira A, Carvalho AB, Tomiyama C, Higa A, Rochitte CE, Santos RD, Canziani MEF. Is coronary artery calcification associated with vertebral bone density in nondialyzed chronic kidney disease patients? Clin J Am Soc Nephrol. 2011:6:1456-62.

8. Watanabe R, Lemos MM, Carvalho AB, Rochitte CE, Santos RD, Draibe SA, Canziani MEF. The association between coronary artery calcification progression and loss of bone density in non-dialyzed CKD patients. Clin Nephrol. 2012;78(6):425-31.

9. Ott SM. Review article: bone density in patients with chronic kidney disease stages 4-5. Nephrology. 2009;14(4):395-403.

10. Carvalho AB, Carneiro R, Leme GM, Rochitte CE, Santos RD, Miname MH, Moyses RM, Jorgetti V, Canziani MEF. Vertebral bone density by quantitative computed tomography mirrors bone structure histomorphometric parameters in hemodialysis patients. J Bone Miner Metab. 2013;31:551-5.

11. Schneider CA, Rasband WS, Eliceiri KW. NIH image to ImageJ: 25 years of image analysis. Nat Methods. 2012;9(7):671-5.

12. Rantalainen T, Nikander R, Heinonen A, Daly RM, Sievanen H. An open source approach for regional cortical bone mineral density analysis. J Musculoskelet Neuronal Interact. 2011;11(3):243-8.

13. Agatston AS, Janowitz WR, Hildner FJ, Zusmer NR, Viamonte M Jr, Detrano R. Quantification of coronary artery calcium using ultrafast computed tomography. J Am Coll Cardiol. 1990;15(4):827-32.

14. Levey AS, Stevens LA, Schmid CH, Zhang YL, Castro AF III, Feldman HI, Kusek JW, Eggers P, Van Lente F, Greene T. Coresh J; CKD-EPI (chronic kidney disease epidemiology collaboration). A new equation to estimate glomerular filtration rate. Ann Intern Med. 2009;150(9):604-12.

15. National Kidney Foundation. KDOQI Clinical practice guidelines for chronic kidney disease: Evaluation, classification, and stratification. Am J Kidney Dis. 2002;39(2 Suppl 1):S1-266.
16. Malluche HH, Blomquist G, Monier-Faugere MC, Cantor TL, Davenport DL. High parathyroid hormone level and osteoporosis predict progression of coronary artery calcification in patients on Dialysis. J Am Soc Nephrol. 2015; 26(10):2534-44.

17. Cejka D, Weber M, Diarra D, Reiter T, Kainberger F, Haas M. Inverse association between bone microarchitecture assessed by HR-pQCT and coronary artery calcification in patients with end-stage renal disease. Bone. 2014;64:33-8.

18. Ok E, Asci G, Bayraktaroglu S, Toz H, Ozkahya M, Yilmaz M, Kircelli F, Sevinc Ok E, Ceylan N, Duman S, Cirit M, Monier-Faugere MC, Malluche HH. Reduction of dialysate calcium level reduces progression of coronary artery calcification and improves low bone turnover in patients on hemodialysis. J Am Soc Nephrol. 2016;27(8):2475-86.

19. Watanabe R, Lemos MM, Manfredi SR, Draibe SA, Canziani MEF. Impact of cardiovascular calcification in nondialyzed patients after 24 months of follow-up. Clin J Am Soc Nephrol. 2010;5:189-94.

20. Tankó LB, Christiansen C, Cox DA, Geiger MJ, McNabb MA, Cumming SR. Relationship between osteoporosis and cardiovascular disease in postmenopausal women. J Bone Miner Res. 2005;20(11):1912-20.

21. Barreto DV, Barreto FC, Carvalho AB, Cuppari L, Draibe SA, Dalboni MA, Moyses RM, Neves KR, Jorgetti V, Miname M, Santos RD, Canziani ME. Association of changes in bone remodeling and coronary calcification in hemodialysis patients: a prospective study. Am J Kidney Dis. 2008;52(6):1139-50.

22. Malluche HH, Davenport DL, Cantor T, Monier-Faugere MC. Bone mineral density and serum biochemical predictors of bone loss in patients with CKD on Dialysis. Clin J Am Soc Nephrol. 2014;9(7):1254-62.

23. West SL, Lok CE, Langsetmo L, Cheung AM, Szabo E, Pearce D, Fusaro M, Wald R, Weinstein J, Jamal SA. Bone mineral density predicts fractures in chronic kidney disease. J Bone Miner Res. 2015;30(5):913-9.

24. Nickolas TL, Stein EM, Dworakowski E, Nishiyama KK, Komandah-Kosseh M, Zhang CA, McMahon DJ, Liu XS, Boutroy S, Cremers S, Shane E. Rapid cortical bone loss in patients with chronic kidney disease. J Bone Miner Res. 2013;28(8):1811-20.

25. Blomquist GA, Davenport DL, Mawad HW, Monier-Faugere MC, Malluche HH. Diagnosis of low bone mass in CKD-5D patients. Clin Nephrol. 2016; 85(2):77-83

26. Jannot M, Mac-Way F, Lapierre V, Lafage-Proust MH. The use of bone mineral density measured by dual energy $\mathrm{X}$-ray absorptiometry (DXA) and peripheral quantitative computed microtomography in chronic kidney disease. J Nephrol. 2017;30(5):635-43.

27. Pocock N. Use of dual energy $X$-ray absorptiometry, the trabecular bone score and quantitative computed tomography in the evaluation of chronic kidney disease-mineral and bone disorders. Nephrology. 2017;22(Suppl 2):19-21.

28. Jamal SA, Gilbert J, Gordon C, Bauer DC. Cortical PQCT Measures are associated with fractures in Dialysis patients. J Bone Miner Res. 2006;21(4):543-8.

29. Nickolas TL, Stein E, Cohen A, Thomas V, Staron RB, McMahon DJ, Leonard $M B$, Shane E. Bone mass and microarchitecture in CKD patients with fracture. J Am Soc Nephrol. 2010;21(8):1371-80,

30. Jamal SA, Cheung AM, West S, Lok C. Bone mineral density by DXA and HR $\mathrm{PQCT}$ can discriminate fracture status in men and women with stages 3 to 5 chronic kidney disease. Osteoporos Int. 2012;23(12):2805-13.

31. Nishiyama KK, Shane E. Clinical imaging of bone microarchitecture with HRpQCT. Curr Osteoporos Rep. 2013;11(2):147-55.

32. Donnelly E. Methods for assessing bone quality: a review. Clin Orthop Relat Res. 2011;469(8):2128-38.

33. Oei L, Koromani F, Rivadeneira F, Zillikens MC, Oei EHG. Quantitative imaging methods in osteoporosis. Quant Imaging Med Surg. 2016;6(6):680-98.

34. Ott SM. Cortical or trabecular bone: what's the difference? Am J Nephrol. 2018:47:373-5.

35. Augati $\mathrm{P}$, Schorlemmer $\mathrm{S}$. The role of cortical bone and its microstructure in bone strength. Age Ageing. 2006:35(S2):ii27-31.

36. Marques IDB, Araújo MJCLN, Graciolli FG, dos Reis LM, Pereira RM, Custódio MR, Jorgetti V, Elias RM, David-Neto E, Moysés RMA. Biopsy vs. peripheral computed tomography to assess bone disease in CKD patients on dialysis: differences and similarities. Osteoporos Int. 2017;28:1675-83.

\section{Publisher's Note}

Springer Nature remains neutral with regard to jurisdictional claims in published maps and institutional affiliations. 